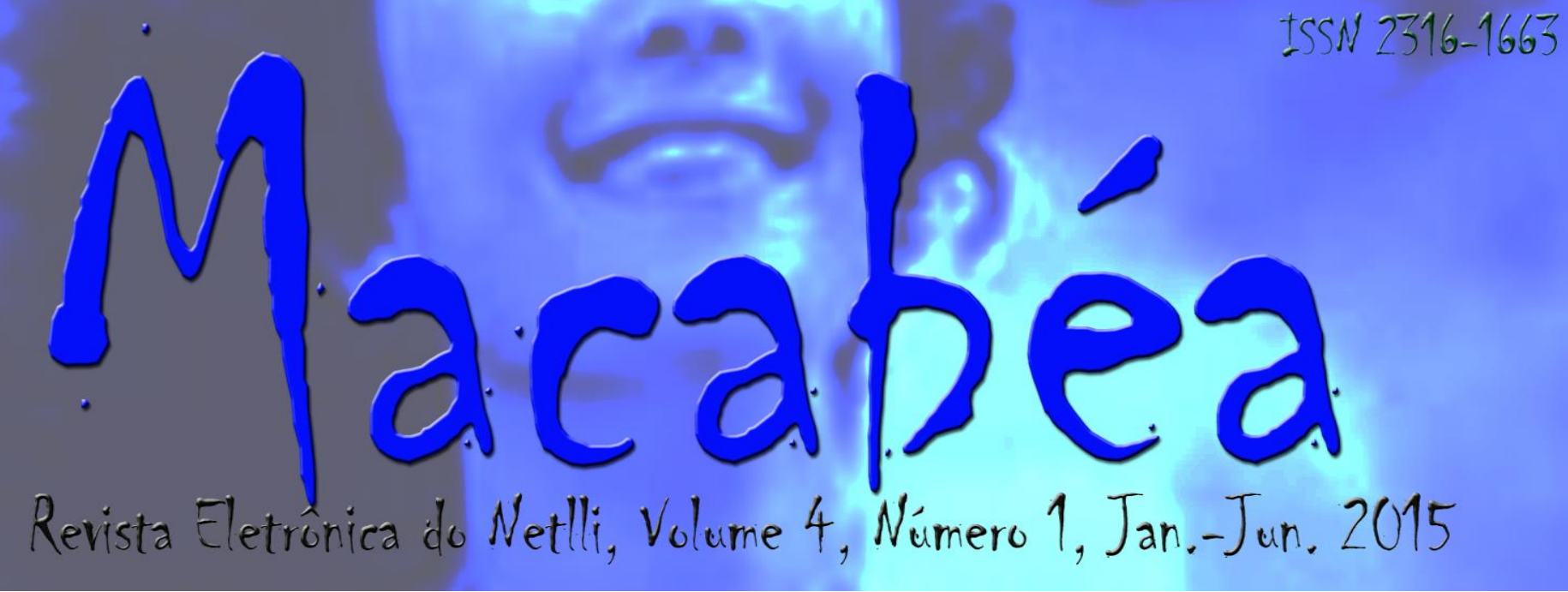

\title{
MOTIVAÇÃO NOSSA DE CADA DIA, DAI-NOS AUTONOMIA E APRENDIZAGEM EM LÍNGUA ESTRANGEIRA HOJE
}

\section{OUR MOTIVATION FROM EVERY DAY, GIVE US THE AUTONOMY AND LEARNING IN FOREIGN LANGUAGE TODAY}

\author{
Eduardo Dias da SILVA \\ UNIVERSIDADE DE BRASÍLIA, Brasil
}

RESUMO | INDEXAÇÃO | TEXTO | REFERÊNCIAS | CITAR ESTE ARTIGO | O AUTOR RECEBIDO EM 12/09/2015 • APROVADO EM 14/09/2015

Abstract

This article comes from a document qualitative research, it is originated in searches for personal and professional explanations that have emerged over the useful readings and thought-provoking debates between language teachers at a university language center on the autonomy and motivation the beginner learners in the appropriation of a foreign language (FL). Initially, we intend to bring the reflection on some definitions given by linguists applied to the constructs autonomy as a complex system, and motivation (one of the factors that influence the various degrees of autonomy), and what are the aspects that collaborate / inhibit this motivation. We realized over the analysis of final reports, which affection is linked to 
motivation, according to some teachers, and that the intrinsic and extrinsic motivations can not be separated from the intentionality of learners.

\section{Resumo}

O presente artigo, oriundo de uma pesquisa qualitativa documental, originou-se nas buscas por esclarecimentos pessoais e profissionais que surgiram ao longo das proveitosas leituras e dos instigantes debates entre professores de línguas, em um centro universitário de línguas, sobre a autonomia e a motivação nos aprendizes iniciantes na apropriação de uma língua estrangeira (LE). Inicialmente, pretende-se trazer a reflexão sobre algumas definições apresentadas por linguistas aplicados sobre os construtos autonomia, como sendo um sistema complexo, e motivação (um dos fatores que influência os diversos graus de autonomia), e quais são os aspectos que colaboram/inibem essa motivação. Percebemos, ao longo das análises dos relatórios finais, que a afetividade está ligada à motivação, de acordo com alguns professores, e que as motivações intrínseca e extrínseca não podem ser separadas da intencionalidade dos aprendizes.

Entradas para indexação

KEYWORDS: Learning beginners. Autonomy. Motivation.

PALAVRAS-CHAVE: Aprendizes Iniciantes. Autonomia. Motivação.

\section{Texto integral}

\section{INTRODUÇÃO}

As pesquisas no campo da autonomia da aprendizagem, ao contrário dos outros ramos seculares das ciências humanas e sociais, iniciaram no início da década de 1960. Yves Châlon e Henri Holec são considerados os pioneiros nos estudos da aprendizagem de línguas e suas contribuições para o entendimento de como se dá a autonomia da aquisição/aprendizagem de língua estrangeira (LE) em jovens e adultos são de grande valia e ainda hoje servem de bases para muitos estudos na área. Portanto, essa preocupação na formação crítica e autônoma do ser humano remota aos tempos clássicos na história da humanidade.

Assim, com a vontade questionadora e inerente dos pesquisadores em Linguística Aplicada, doravante LA, este trabalho tem como intuito responder às inquietações sobre os construtos motivação e autonomia - entende-se este dentro do paradigma da teoria da complexidade, não como uma simples metáfora, mas sim como um novo paradigma em ciências, no qual oferece conceitos para ajudar a entender os diferentes fenômenos nos diferentes campos do conhecimento, incluso a Linguística Aplicada - de acordo com Larsen-Freeman (1997; 2008). Em seu trabalho inaugural, dentro dessa nova perspectiva, que apresenta o conceito de imprevisibilidade, característica dos sistemas complexos, segunda a autora, que é a 
tônica das nossas análises documentais ao se debruçar nos relatórios finais produzidos ao longo dos cursos livres de LE ministrados em um centro universitário de línguas.

Segundo a teoria do caos/complexidade, pequenas mudanças podem resultar em grandes diferenças na motivação em sala de aula de centro universitário de línguas e, por conseguinte, possibilita responder aos questionamentos investigativos nos processos de aprendizagem em relação à autonomia. Para isso, utilizaremos as análises documentais dos relatórios finais de cursos livres de LE de um centro universitário de línguas. Segundo Bell (2002, p. 207),

a investigação através de narrativas se baseia em pressupostos epistemológicos da produção de sentido por seres humanos a partir de experiências aleatórias. Os pesquisadores selecionam os elementos da experiência nos quais têm interesse e os categorizam de forma a refletir os conceitos e crenças subjacentes à narrativa.

O valor documental não está intimamente ligado somente ao produto escrito, "o termo documental alude a materiais escritos, visuais ou físicos", conforme afirma Merriam (1998, p. 112). Na análise documental há, caso necessário, a opção de analisar as informações contidas nos documentos concomitantemente com outros instrumentos de coletas (entrevistas) e/ou outros instrumentos de registros, que não foram aplicados a esta pesquisa. Em todos os casos, o primordial é que tais documentos sejam relevantes ao estudo em questão. No que tange ainda à definição de análise documental, Santos (2013), concebe que

[...] é um meio de pesquisa e de geração de dados que, em pesquisas de natureza qualitativa, pode tanto servir para complementar informações já obtidas via outras técnicas quanto evidenciar novos aspectos ligados a uma temática específica ( $\mathrm{p}$. 107).

Nesta pesquisa, os documentos (relatórios finais de cursos livres de LE) foram fontes que forneceram dados referentes a autonomia e a motivação nos aprendizes iniciantes na apropriação de uma língua estrangeira (LE) para serem analisados "sistematicamente". Portanto, os documentos são como "quaisquer materiais escritos que possam ser usados como fonte de informação sobre o comportamento humano", conforme Phillips (1974, p. 187 apud LÜDKE; ANDRÉ, 1986, p. 38), tais quais leis, diários, jornais, revistas, discursos, livros, arquivos escolares, entre outros de acordo com Lüdke e André (1986) e Flick (2009).

Há outra definição, bastante relevante, para documentos que traduz melhor a concepção que se tem em relação a eles, que é a seguinte: 
Se tivermos que arcar com a natureza dos documentos, então precisaremos afastar-nos de um conceito que os considere como artefatos estáveis, estáticos e pré-definidos. Em vez disso, devemos considerá-los em termos de campos, de estruturas e de redes de ação. De fato, o status das coisas enquanto "documentos" depende precisamente das formas como esses objetos estão integrados nos campos de ação, e os documentos só podem ser definidos em relação a esses campos (PRIOR, 2003, p. 2 apud FLICK, 2009, pp. 230-231).

É de se vislumbrar, a partir desta citação, que documentos são despidos de uma concepção estável, ou seja, eles são retirados de uma forma com molde fixo e preestabelecido, passando a significar registros escritos/visuais/auditivos inseridos em um momento sócio-histórico específico. Os significados dos documentos, nestes termos, são construídos a partir da inserção no social, momento em que documentos e meio social se relacionam dialeticamente.

\section{AUTONOMIA}

No artigo de Moura Filho (2009), que trata do estado-de-arte da autonomia, encontra-se definições de diversos teóricos da autonomia de aprendizagem de línguas, por ser, de certa forma, uma área em pleno e recente desenvolvimento de teorias que a fomentam/validam.

Por meio desse autor, vislumbram-se várias definições disseminadas por pesquisadores, como Benson, Dickinson, Little, Littlewood, Holec, Paiva dentre outros. No entanto, podemos encontrar alguns pontos em comum entre as definições apresentadas pelos teóricos, a saber.

Segundo Holec (apud MOURA FILHO, 2009), autonomia são situações nas quais o aprendiz estuda totalmente por conta própria - diferente de ser autodidata ou autossuficiente, estes não são sinônimos de autonomia; Autonomia também é, segundo Moura Filho (2009, p. 87) "o conjunto de habilidades que podem ser aprendidas e aplicadas na aprendizagem autodirigida". Interessante frisar que o aprendiz sendo um ser social multifacetado e subjetivo requer uma análise social, política e cognitiva na aplicabilidade e na aprendizagem desses conjuntos de habilidades que levam à autonomia, pois não podemos tratar os aprendizes como sendo homogêneos, conforme Paiva (2011). Assim, o percurso do aprendiz de uma língua materna para aprendiz de uma segunda língua, ou língua estrangeira, é um fenômeno complexo que acontece entre a ordem total e o caos, ou seja, a imprevisibilidade.

Percebe-se, também, que há evidências suficientes para se postular que a autonomia na aprendizagem de Língua Estrangeira (LE) é um sistema complexo 
adaptativo - complexo pela dificuldade de descrição e adaptativo pela capacidade de adaptação às diferentes condições que lhe são impostas pelo ambiente e pelos agentes, neste caso a sala de aula e os professores e os aprendizes, respectivamente, como elucida Paiva (2008).

Segundo a visão cognitivista preconizada por Thanasoulas (apud MOURA FILHO, 2009, p. 92), autonomia "é capacidade inata que é suprimida pela educação institucionalizada". Vale destacar, que não percebamos a educação institucionalizada como supressora, tendo em vista que a autonomia é preparar o aprendiz para ser um indivíduo politizado e crítico do seu fazer.

Essa visão defendida por Benson, Pennycook e Young, basicamente traz uma versão política como sendo um controle sobre os processos e o conteúdo da aprendizagem e a autonomia como um fator de transformação/manutenção dos padrões sociais. Logo a autonomia serve para manter as normas político-sociais de uma determinada sociedade, pois há no mínimo dois padrões de interpretação da autonomia: ocidental, visão amplamente européia, e oriental.

Outro conceito apresentado por Moura Filho (2009), diz respeito a autonomia ser exercício da responsabilidade pelos aprendizes por sua própria aprendizagem. 0 senso crítico (visão cognitiva) é algo bem trabalhado na autonomia no que tange as escolhas dos aprendizes de como, quando, onde e o que aprender, com ou sem o auxílio/orientação do professor e a importância dessa aprendizagem para a sua vida social, política e para o desenvolvimento psíquico. Logo um ser plural e complexo.

Resumindo o pensamento de Macaro (1997, apud MOURA FILHO, 2009, p. 78), "autonomia seria o direito dos aprendizes de determinarem a direção de sua própria aprendizagem". Ou seja, o aprendiz assume a responsabilidade e a tomada para si das decisões/escolhas de objetivos, conteúdos, promoção, métodos e técnicas de aprendizagem e também tornar-se responsável pelos passos, ritmos e avaliações desse processo.

Na leitura de Benson (1996, apud MOURA FILHO, 2009, pp. 86-88) sobre autonomia, na qual ele a (re)classifica, dentro do processo de aprendizagem, autônomo como sendo:

a) técnica que vislumbra o ato de aprender uma língua estrangeira fora do ambiente de uma instituição educacional e sem a intervenção de um professor b) psicológica, que define a capacidade que permite aos aprendizes ter mais consciência da responsabilidade de seus papéis no próprio aprendizado; c) política, que, simplesmente, é o controle sobre os processos e conteúdos da aprendizagem.

Verifica-se que essa conceituação de Benson tem uma base nos posicionamentos das principais correntes filosóficas no que tange o conhecimento 
e aprendizagem na ciências humanas e sociais, positivismo, construcionismo e teoria da crítica social. 0 indivíduo, como sendo complexo e multifacetado, busca na autonomia da aprendizagem de línguas sua formação como aprendiz autônomo, pessoa autônoma e comunicador autônomo, pois, por definição, o objetivo de toda e qualquer educação é ajudar os indivíduos a pensar, agir, e aprender, independentemente, em relevantes áreas de suas vidas (LITTLEWOOD apud MOURA FILHO, 2009).

\section{MOTIVAÇÃO}

A maioria dos pesquisadores e educadores concordam que a motivação é muito importante na autonomia da aprendizagem de línguas. Segundo Van Lier (1996; 2002; 2004), mesmo sem ser superdotados, as pessoas não podem realizar seus objetivos a longo prazo, qualquer que seja o currículo e quem quer que seja o professor, sem levar em conta a motivação. 0 conceito de motivação da aprendizagem de línguas tornou-se central para uma série de teorias de aquisição de Língua Segunda (L2), ou Língua Estrangeira (LE), por Krashen (1981) e Gardner (1985), respectivamente e a motivação tem sido amplamente aceita pelos professores e pesquisadores como um dos principais fatores influenciadores das taxa de sucesso na apropriação de aprendizagem autônoma de LE.

Podemos dizer, tendo como base nossas leituras, que todos os outros fatores envolvidos na apropriação de LE pressupõem a motivação, até certo ponto. Claro, que existem fatores de desmotivação que afetam/inibem o desenvolvimento da autonomia da aprendizgem em LE, no entanto, neste artigo, nos limitaremos às análises no que tange a manutenção ou desenvolvimento da motivação por parte dos aprendizes iniciantes, como argumentado por Van Lier (2004, p. 108), "quando dizemos algo, nós não apenas fornecemos uma informação sobre uma coisa ou outra, nós também fornecemos, ao mesmo tempo, informação sobre duas questões importantes: quem nós somos, e quem nós pensamos que somos".

Motivação vem sendo tradicionalmente entendida como tendo uma orientação instrumental ou integrativa, como proposto por Gardner e Lambert (1972). Estes autores definem a motivação integrativa como "uma vontade de se tornar um membro de outro grupo etnolinguística" (GARDNER; LAMBERT, 1972, p. 12), enquanto a orientação instrumental é "caracterizada por um desejo de obter reconhecimento social ou vantagem econômica através do conhecimento de uma língua estrangeira" (GARDNER; LAMBERT, 1972, p. 14).

Posteriormente, Deci e Ryan (1991, p. 46) desenvolveram "a teoria da auto-determinação" e acrescentou-se no campo da motivação duas outras subdivisões: "motivação intrínseca", que se refere, basicamente, a fazer algo porque é inerentemente interessante ou agradável; e "motivação extrínseca", que se refere a fazer algo de forma instrumentalizada.

Estes mesmos autores entendem e exemplificam a função instrumentalizadora da motivação extrínseca como um aprendiz que adquire uma 
LE para evitar possíveis sanções/castigos dos pais que o obriga a estudar, ou um outro aprendiz que estuda uma LE, pensando na importância desta na sua carreira profissional.

Vislumbramos, então, a motivação na perspectiva das teorias da Complexidade e do Caos preconizada na Linguística Aplicada, doravante LA, por Larsen-Freeman (1997), no qual a motivação na aquisição/aprendizagem é um sistema complexo não linear, mostrando que ambos, a aquisição e a aprendizagem têm as mesmas características apontadas por pesquisadores da Complexidade são dinâmicos, complexos, não-lineares, caóticos, imprevisíveis, sensíveis às condições iniciais, abertos, auto-organizados, sensíveis à feedback e adaptáveis.

Todas essas definições de motivação corroboram para o nosso entendimento do construto de uma maneira geral. Entretanto, compartilhamos com Dörnyei $(2011)$ e Paiva $(2008 ; 2011)$ quando afirmam que essas teorias não são necessariamente excludentes, mas, simplesmente, se interessam por diferentes fases/momentos de um motivado processo comportamental, considerando, também, que a motivação é um importante subsistema complexo inserido nos sistemas de aquisição/aprendizagem autônoma.

Assim, percebemos o construto motivação como sendo complexo, multidimensional, não somente um problema de integração entre falantes de uma comunidade, nem vislumbramos seu uso de forma instrumentalizada para obtenção de vantagens ou exibições de motivações de maneira intrínseca ou extrínseca; Vislumbramos a motivação como uma força dinâmica e plural, envolvendo aspectos social, afetivo e cognitivo e não havendo uma rigidez nos padrões, pois motivação varia de acordo com os estágios da vida e os períodos temporais, conforme Paiva (2011). É interessante lembrar, que motivação não se restringe somente ao contexto educacional, ela é uma condição necessária para autonomia.

\section{METODOLOGIA}

As análises dos relatórios finais, como adverte Pavlenko (2002), não são meras produções individuais, mas artefatos que sofrem interferência das convenções sociais, culturais - raça, etnia, classe social, gênero, sexualidade - e históricas, incluindo a interação com o leitor (real ou imaginário) e o propósito para o qual o relatório foi produzido.

Assim, as análises dos relatórios finais dos cursos livres de LE permitem ao pesquisador compreender a motivação de diferentes professores de línguas estrangeiras, recolher informações sobre as quais os professores não têm consciência; iluminar a noção temporal da motivação, "reconhecendo que a compreensão sobre as pessoas e sobre os eventos muda com o tempo" (BELL, 2002 p. 209). Para verificar se a autonomia na aprendizagem de LE, realmente, se comporta como um sistema complexo, optamos por trabalhar com as análises de 
relatórios finais (perspectiva documental) elaborados ao final de cada curso livre de LE pelos professores regentes no centro universitário de línguas da Universidade de Brasília, doravante PPE/UnB Idiomas.

Serviram de base documental, os relatórios finais dos cursos livres de LE ministrados ao longo de 2012-2013, para a coleta de dados no Programa Permanente de Extensão UnB Idiomas - PPE/UnB Idiomas - no qual expressamos aqui nossos agradecimentos aos professores e à instituição (Universidade de Brasília) que possibilitaram a pesquisa e a elaboração deste artigo.

\section{CONSIDERAÇÕES FINAIS}

Primeiramente, este artigo não tem como objetivo findar o assunto motivação e, autonomia dos aprendizes iniciantes de línguas em centro universitário e, sim, lançar mais uma luz ao debate e à pesquisa desses construtos como pertencentes ao paradigma das teorias da Complexidade e do Caos. Percebemos, ao longo das análises dos relatórios finais, que a afetividade está ligada à motivação, de acordo com alguns professores, e que as motivações intrínseca e extrínseca não podem ser separadas da intencionalidade dos mesmos.

Chamamos este fenômeno de dicotomia de motivação, pois são motivações distintas que no decorrer do desenvolvimento da aprendizagem, ou do momento vivido pelo aprendiz, uma ou outra se torna mais preponderante, mas nunca excludentes. Acredita-se que o aprendiz é, sim, e não somente, regido por fatores motivacionais que o condicionam a querer aprender uma língua estrangeira.

Percebemos também que os pressupostos da teoria do caos/complexidade estão presentes em todos os relatos dos professores de LE analisados, em maior ou menor proporcionalidade, e outros fatores sociais, tais como poder aquisitivo, localidade geográfica, grau de instrução, influenciaram tanto a motivação quanto a aprendizagem autônoma da língua estrangeira (LE), tornando-as não linear.

Assim, o paradigma da teoria do caos/complexidade, que se preocupa com o comportamento dos sistemas dinâmicos, ou seja, aqueles que mudam com o tempo, e propõe uma visão holística desses sistemas, oferece à Linguística Aplicada uma forma inovadora de refletir sobre a motivação em aprendizes iniciantes.

De acordo com Oliveira (2011), a teoria do caos e a teoria da complexidade, muito embora sejam hoje intimamente interligados, têm origens etimológicas e epistemológicas distintas. Serviram muito bem ao propósito de base teórico-metodológica para a aplicação e elaboração deste artigo. No plano histórico do desenvolvimento do saber ocidental, os vocábulos caos e complexidade têm raízes no mundo clássico Greco-romano. No seu uso atual no fazer cientifico, é possível perceber que, enquanto conceitos formais, as teorias do caos e da complexidade moldaram-se em campos diversos de investigação das ciências sociais. 


\section{Referências}

BELL, J. S. Narrative inquiry: More than just telling stories. TESOL Quarterly, 36, 2, 2002. pp. 207-212.

DECl, E. L.; RYAN, R. M. A motivational approach to self: Integration in personality. In: DIENSTBIER, R. (Org.). Nebraska symposium on motivation: Perspectives on motivation. Lincoln, University of Nebraska Press, v. 38, pp. 237-288, 1991.

DÖRNYEI, Z. Motivação em ação: Buscando uma conceituação processual da motivação de alunos. Em: BARCELOS, A. M. F. (Org.). Linguística aplicada: Reflexões sobre ensino e aprendizagem de língua materna e língua estrangeira. São Paulo. Pontes. 2011. p.199-236.

FLICK, U. Redação e o futuro da pesquisa qualitativa: arte ou método? Em: Introdução à pesquisa qualitativa. Porto alegre: Artmed, 2009. pp. 369-379.

GADNER, R. C. Social Psychology and Language Learning: The role of attitudes and motivation. Londres: Edward Arnold. 1985.

.;LAMBERT, W. E. Attitudes and motivation in second-language learning. Rowley, Massachussetts: Newbury. 1972.

KRASHEN, S. D. Second language Acquisition and Second language Learning. New York. Pergamon. 1981.

LARSEN-FREEMAN, D. Chaos/complexity science and second language acquisition. Applied Linguistics, v. 18, n. 2, p. 141-165, 1997.

. ; CAMERON, L. Complex systems and applied linguistics. Oxford: Oxford University Press, 2008.

LÜDKE, M.; ANDRÉ, M. E. D. A. Pesquisa em educação: abordagens qualitativas. São Paulo: EPU, 1986.

MERRIAM, S. B. Qualitative research and case study applications in education: revised and expanded from Case Study Research. São Francisco, Califórnia: Jossey-Bass Publishers. 1998.

MOURA FILHO, A. C. L. O que há em um nome? O estado-da-arte da autonomia na aprendizagem de línguas. Linguagem e ensino, Pelotas, v.12, n. 1, p. 253-283, jan./jun. 2009.

OLIVEIRA, R. A. Complexidade: conceitos, origens, afiliações e evoluções. Em: PAIVA, V. L. M. O; NASCIMENTO, M. (Orgs.). Sistemas Adaptativos Complexos: Lingua(gem) e Aprendizagem. Campinas: Pontes, 2011. p. 13-34.

PAVLENKO, A. Narrative study: Whose story is it, anyway? TESOL Quarterly, 36, 2, 2002. p.213218.

PAIVA, V. L. M. O. Identity, motivation, and autonomy from the perspective of complex dynamical systems. In: MURRAY, G.; GAO, X.; LAMB, T. Identity, motivation and autonomy in language learning. Bristol, Buffalo, Toronto. Multilingual Matters, 2011, p. 57-72.

Multimedia language learning histories. Em: KALAJA, P.; ; BARCELOS, A. M. (Eds.).

Narratives of learning and teaching EFL. London: Palgrave Macmillan, 2008. p. 199-213.

SANTOS, M. S. A construção de identidades no livro didático de língua estrangeira: uma perspectiva crítica. Dissertação de Mestrado. 239f. Mestrado em Linguística Aplicada. LET-UnB. Brasília, 2013.2 Disponível em: <http://pgla.unb.br/index.php?option=com content\&view=article\&id=435:marcelo-sousasantos\&catid=42:2013\&ltemid=271 > acesso em 13 de janeiro de 2015.

VAN LIER, L. Interaction in the language curriculum: awareness, autonomy \& authenticity. London: Longman. 1996. 
From input to affordance: social-interactive learning from an ecological perspective. In: LANTOLF, J. (Ed.). Sociocultural theory and second language learning. Oxford: Oxford University Press, 2002

The ecology and semiotics of language learning: a sociocultural perspective. Boston: Kluwer Academic, 2004.

\section{Para citar este artigo}

SILVA, Eduardo Dias da. Motivação nossa de cada dia, dai-nos autonomia e aprendizagem em língua estrangeira hoje. Macabéa - Revista Eletrônica do Netlli, Crato, v. 4, n. 1, p. 57-66, jan.jun. 2015.

\section{0 autor}

Eduardo Dias da Silva é Mestre em Linguística Aplicada pelo Departamento de Línguas Estrangeiras e Tradução - LET da Universidade de Brasília - UnB (2014), Especialista em Metodologia no Ensino de Língua Portuguesa e Estrangeira pelo Centro Universitário Internacional - UNINTER (2013), licenciado em Letras Língua Francesa e respectiva literatura pela Universidade de Brasília - UnB (2006). Integrante do Núcleo de Estudos Críticos e Avançados em Linguagem (NECAL/PPGL/UnB) filiado ao Grupo de Pesquisa CNPq em Educação Crítica de Profissionais da Linguagem para além-mar: Políticas linguísticas, Identidades, Multiletramentos e Transculturalidade, membro da Associação Brasileira de Linguística (ABRALIN), da Associação de Linguística Aplicada do Brasil (ALAB) e da Associação de Professores de Francês do Distrito Federal (APFDF). Atualmente, professor de Educação Básica na Secretária de Estado de Educação do Distrito Federal - SEEDF (2014), ministrando aulas de francês língua estrangeira (FLE) no Centro Interescolar de Línguas de Sobradinho - CILSob/DF. Tendo a Didática de Línguas, a Oralidade do FLE, os estudos sobre Gêneros Discursivos, as Teorias Curriculares, os (Multi)Letramentos em ambientes de ensino-aprendizagem, bem como a Formação de Professores como norteadoras das minhas atividades e interesses de pesquisa e ensino em uma perspectiva transdisciplinar em Linguística, Linguística Aplicada (Crítica), Literatura, Educação e ciências afins. 